\title{
Geo-gebra como herramienta didáctica en el proceso de enseñanza-aprendizaje de la matemática, y su incidencia en el rendimiento académico en los estudiantes de la carrera de ingeniería agronómica
}

Geo-gebra como herramienta didáctica en el proceso de enseñanzaaprendizaje de la matemática, y su incidencia en el rendimiento académico en los estudiantes de la carrera de ingeniería agronómica

Juan Manuel Martínez Nogales. ${ }^{1}$, Jorge Cachuput Gusñay. ${ }^{2}$, Hernan Eriberto Chamarro Sevilla. ${ }^{3}$ \& Jorge Rigoberto López Ortega. ${ }^{4}$

\begin{abstract}
.
The Geo-Gebra software as a didactic tool in the teaching-learning process of mathematics and its impact on academic performance in the first semester students of the Faculty of Natural Resources, Agronomic engineering career of ESPOCH. The problem that has been detected in the students of the first semester, a high rate of low performance in the learning of mathematics, in the race because there is a culture of learning on the part of the students, it is determined that we must make profound changes in educational paradigms, the proposal for this process is to use the Geo-Gebra software didactic tool of mathematics, for the research was based on a questionnaire of questions applied with respect to the use of GoeGebra software, as a teaching resource in teaching- learning of mathematics, then with the use of this tool a form of satisfaction was applied to students and teachers, to later make the didactic guide using the Geo - Gebra educational software, hence the importance of making striking designs according to the level or semester and with contents attached to the current geometry plans and programs in which educational. According to the work experience, a didactic guide was designed for the use of educational software specifically for inequations.

${ }^{1}$ Escuela Superior Politécnica de Chimborazo, Facultad de Recursos Naturales. Riobamba, Ecuador. jumartinez@espoch.edu.ec

${ }^{2}$ Escuela Superior Politécnica de Chimborazo, Facultad de Recursos Naturales. Riobamba, Ecuador. jorge.cachuput@espoch.edu.ec

3 Escuela Superior Politécnica de Chimborazo, Facultad de Recursos Naturales. Riobamba, Ecuador. hernan.chamorro@espoch.edu.ec

4 Escuela Superior Politécnica de Chimborazo, Facultad de Recursos Naturales. Riobamba, Ecuador. jorge.lopezo@espoch.edu.ec
\end{abstract}


It is concluded the research carried out that $72 \%$ of the students surveyed consider, using the ICTs it would improve the learning of the geometry and its academic performance; Therefore, it is recommended to train the teachers of the area and promote the proposal in the institution for the application in the teaching-learning process.

Keywords: GeoGebra software, TIC information and communication technologies, teaching-learning, academic performance, didactic resource

\section{Resumen.}

El software Geo-Gebra como herramienta didáctica en el proceso de enseñanza-aprendizaje de la matemática y su incidencia en el rendimiento académico en los estudiantes del primer semestre de la Facultad de Recursos Naturales, Carrera de ingeniería agronómica de la ESPOCH. el problema que se ha detectado en los estudiantes del primer semestre, un alto índice de bajo rendimiento en el aprendizaje de la matemática, en la carrera debido a que existe una cultura de aprendizaje por parte del estudiantado, se determina que debemos realizar cambios profundos de paradigmas educativos, la propuesta para este proceso es utilizar el software Geo-Gebra herramienta didáctica de la matemática, para la investigación se partió de un cuestionario de preguntas aplicadas con respecto a la utilización de software Goe-Gebra, como recurso didáctico en la enseñanza- aprendizaje de la matemática, luego con el uso de esta herramienta se aplicó un formulario de satisfacción a los estudiantes y docentes, para posteriormente realizar la guía didáctica utilizando el software educativo Geo - Gebra, de ahí la importancia de realizar diseños llamativos acordes al nivel o semestre y con contenidos apegados a los planes y programas de geometría vigentes en el que hacer educativo. De acuerdo a la experiencia de trabajo, se diseñó una guía didáctica para el uso del software educativo específicamente para las inecuaciones. Se concluye la investigación realizada que el $72 \%$ de estudiantes encuestados consideran, usando las TICS mejoraría el aprendizaje de la geometría y su rendimiento académico; por ello se recomienda capacitar a los docentes del área y promover la propuesta en la institución para la aplicación en el proceso enseñanza aprendizaje

Palabras claves: software GeoGebra, tecnologías de la información y comunicación TICs, enseñanza-aprendizaje, rendimiento académico, recurso didáctico

\section{Introducción.}

La sociedad moderna basada en el conocimiento, en donde la calidad, rapidez, seguridad y acceso a la información juegan un papel fundamental, la incorporación de la tecnología en los diferentes ámbitos del ser humano es prácticamente inevitable y su dependencia pareciera no detenerse, siendo en la educación donde mayormente están presente. La combinación de las tecnologías y la pedagogía da lugar a lo que se denomina las Tecnologías de la Información y Comunicación (TIC). 
Por lo tanto, las herramientas informáticas están disponibles, pudiendo potenciar nuevas formas de concebir los procesos de enseñanza y aprendizaje, en donde tanto docentes como alumnos se benefician.

El desarrollo del presente trabajo de investigación se realiza basado en que los últimos años se ha notado que la evolución de la tecnología y al mismo instante se ha incorporado en el ámbito de la formación educativa mediante la web, aulas virtuales, programas, software, ordenadores etc. En esta ocasión se ha escogido un programa de software libre Geo-Gebra como uno de las formas y recursos didácticos para el mejoramiento y aprendizaje de la Matemática en los estudiantes de primer semestre de la carrera de agronomía en la Facultad de Recursos Naturales de la ESPOCH. Comenzaremos identificando el problema que se ha notado en los estudiantes, en donde se detalla ciertas causas que provocan un deficiente aprendizaje de la matemática y deserción de la población estudiantil, es por ello que en la presente investigación se determinara la importancia del software Geo-Gebra para la mejora del aprendizaje de la matemática, como primer paso se realizara una delimitación del problema para lo cual se aplicará la solución posible por medio de estudios con los estudiantes del primer semestre de la carrea de Agronomía se hará constar la problematización, sistematización del problema detectado, se identificará los métodos utilizados por los docentes en la enseñanza de la matemática, justificando la investigación por medio de contenidos (teórica, metodológica, práctica); objetivos (general y específicos); marco hipotético (hipótesis); Operacionalización de las variables.

\section{Perspectiva Histórica}

Es la oportunidad para que los docentes ayudemos a nuestros estudiantes en la comprensión del tema a través de una estrategia metodológica ya antes establecida pero poco aplicada en muchas asignaturas, quizá por el tiempo que ello involucra o por conservar el tradicionalismo. Sin embargo, existe la aceptación de los estudiantes por la aplicación de las TICS para la comprensión de ciertos temas que hace que la propuesta sea factible [1].

Las inecuaciones y las Gráficas son temas matemáticos de base fundamental, para el desarrollo de los demás temas en los niveles siguientes de la carrera. "Por ser las inecuaciones con sus gráficas una de las áreas con mayor capacidad de aplicación, se constituye en una herramienta fundamental para todo estudiante del décimo año.

\section{Justificación}

Ésta investigación tiene como propuesta la utilización de una Guía Didáctica del Uso del Software GeoGebra como herramienta pedagógica, debido a que se hace difícil para docentes y estudiantes realizar las prácticas de los temas de inecuaciones y sus gráficas solamente en papel milimetrado, es decir el método tradicional, pero debido al alto porcentaje de aceptabilidad de la Utilización del Software Geo-Gebra, hace que los estudiantes se motiven y vean más atractiva e interesante a los temas de ésta propuesta.

La investigación realizada tiene como visión, diseñar su propio conocimiento a través de una guía metodológica de la utilización del Geo-Gebra. Para lograr este objetivo se propone que el estudiante-docente trabajen en diferentes contextos: numérico, algebraico y de aplicación $[1]$. 
Al involucrar habilidades mentales, tales como: observación, deducción, predicción conllevan a que los estudiantes desarrollen su propio conocimiento. Ante estas situaciones didácticas se espera favorecer el aprendizaje significativo, con el propósito de incidir positivamente en la enseñanza-aprendizaje de las inecuaciones de primer grado.

La creación de la guía metodológica del Uso del Laboratorio Virtual, de la manera más simple y sencilla, hace que los estudiantes mejoren considerablemente su interés, motivación en los temas de esta propuesta y por ende mejoren su rendimiento académico.

\section{Problema}

En los estudiantes del primer semestre de la carrera de Agronomía de la Facultad de Recursos Naturales de la ESPOCH; se ha detectado falencias en cuanto a la utilización de la tecnología en la asignatura de Matemática, debido a muchos factores que están relacionados con las estrategias metodológicas que se utiliza por parte de los docentes de esta institución.

Se puede decir que la enseñanza-aprendizaje de la matemática está motivada por la aplicación de procesos tradicionales, sin darle paso a la tecnología y al razonamiento.

La inclusión de las Tics, en la enseñanza-aprendizaje de la matemática es una estrategia metodológica motivadora, donde el estudiante a través de la experimentación con el software Geo-Gebra logrará identificar las características del tema objeto de estudio, valorando el potencial dinámico del software con respecto al trabajo con lápiz y papel. [2]

Los docentes en promedio tienen conocimientos básicos computacionales, pero muy pocos lo utilizan como soporte para dictar sus clases, tampoco se cuenta con la oferta de cursos regulares de computación dirigidos a docentes, [3], acceso a internet, uso de bibliotecas virtuales dentro de la institución, redes sociales, entre otros.

Las nuevas políticas educativas en el Ecuador y a nivel general los nuevos paradigmas en el entornos del aprendizaje, y en todos niveles de educación en especial de la general básica donde se viene impulsando la utilización de plataformas web, la multimedia, programas, ordenadores, software educativo, herramientas de software libre y privado, que favorecen los procesos de enseñanza aprendizaje, permitiendo consolidar y fundamentar el [1] .

En la actualidad en todos los niveles las herramientas, recursos, estrategias metodológicas y medios tecnológicos utilizados en la enseñanza por parte del docente [4] y por el mismo estudiante, han hecho que experimenten profundos cambios de lo tradicional a la adquisición de conocimientos mediante el descubrimiento (paradigma constructivista), [5] en la que el docente debe convertirse en orientador, coordinador, guía, andamio para que el estudiante llegue al conocimiento.

\section{Objetivos y Metodología de la propuesta de la investigación Objetivo General}

Determinar la incidencia en la utilización del software Geo-Gebra como herramienta didáctica de la matemática, en el rendimiento académico en los estudiantes de primer semestre de la carrea de Agronomía de la ESPOCH 


\section{Objetivos Específicos}

- Diagnosticar que tipo de tecnología están utilizando los docentes de matemática en la carrera

- Realizar un análisis comparativo en el rendimiento académico de los estudiantes de un grupo control y de los estudiantes de experimentación

- Proponer y Diseñar una guía didáctica con la utilización del software Geo-Gebra, como una herramienta didáctica-pedagógica para mejorar el rendimiento de los estudiantes de la carrera para resolver un sistema de inecuaciones de primer grado con dos variables.

\section{Metodologia.}

La metodología utilizada en la propuesta refiere a los métodos: inductivos-deductivo y heurístico.

Se considera como estrategias al trabajo grupal e individual en el uso de las herramientas tecnológicas aplicadas en los diferentes temas a tratarse.

\section{EI software libre y la educación.}

La libertad del software asume un rol de especial importancia en el ámbito educativo. Las instituciones educativas de todos los niveles deben utilizar y enseñar exclusivamente software libre porque es el único que les permite cumplir con sus misiones fundamentales: difundir el conocimiento y enseñar a los estudiantes a ser buenos miembros de su comunidad. El código fuente y los métodos del software libre son parte del conocimiento humano.

Al contrario, el software privativo es conocimiento secreto y restringido, y por lo tanto, se opone a la misión de las instituciones educativas. El software libre favorece la enseñanza, [7] mientras el software privativo la prohíbe.

El software libre no es simplemente un asunto técnico, es un asunto ético, social y político, es decir debe ser política de estado la aplicación de software libre en todas las actividades públicas. Es una cuestión de derechos humanos que los usuarios de software deben tener [8]. La libertad y la cooperación son valores esenciales del software libre.

El sistema GNU pone en práctica estos valores y el principio del compartir, pues compartir es bueno y útil para el progreso, desarrollo de la humanidad y no solo en provecho de una o varias personas. Aunque la industria de la información ha ayudado muchísimo a la divulgación y popularización del conocimiento humano, también ha generado efectos colaterales negativos: un mercado altamente discriminatorio. Sólo podían acceder a la información, y por supuesto al conocimiento humano, aquellos que tenían dinero para pagarla.

A medida que las civilizaciones se hacían más sofisticadas, especialmente después de la edad media, el acceso al conocimiento se hizo imprescindible, [9] y la discriminación del propio mercado se hizo insostenible. 
Desde las herramientas básicas para preparar alimentos, pasando por la rueda, hasta todos los conocimientos de física, electrónica, campos magnéticos, partículas subatómicas, ondas, visión humana, óptica... etc. para que ahora lleguen unas enormes multinacionales como si eso lo hubiesen podido lograr solos, sin el aporte de millones y millones de meses hombre y capital público invertidos. Muchos nos preguntamos cómo es posible que la misma comunidad a la que se le arrebata el derecho a acceder a su conocimiento, esté de acuerdo con esa apropiación y uso unilateral del mismo [10].

Por eso la primera razón por la cual una institución como cualquier institución educativa pública debe utilizar software libre es justamente que para eso mismo ha surgido para favorecer la divulgación del ya vasto conocimiento humano y esto es imposible de lograr utilizando sistemas que ponen todo tipo de trabas a la libertad de copiar y utilizar el conocimiento. Además, el uso de software libre en la educación tiene una gran cantidad de beneficios.

¿Por qué cuando se enseña informática, sí parece razonable enseñar a usar una determinada marca de programas? [1] ¿Hay razones para eso? Utilizando software libre, más que enseñar a utilizar un producto se enseña a utilizar una tecnología, ya que este se apoya en estándares libres y reconocidos.

Un usuario de un sistema privativo como por caso Microsoft Windows o Microsoft Office se sentirá desorientado al intentar utilizar cualquier otro sistema que cumpla la misma función debido a que estos imponen una forma de trabajo no estandarizada y cerrada en la cual no es posible ver el funcionamiento transparente de ningún proceso [11]. Esto no ocurrirá con un usuario de GNU/Linux o de cualquier otro sistema libre. Se debe mostrar que el software libre le permite al estudiante poner en juego todas sus habilidades, capacidades, inteligencia, destrezas etc., lo que no le permite el software privado por las restricciones, en donde debe seguir un esquema, una estructura, un paradigma preestablecido por una institución, grupo de personas o sociedades con fines de lucro.

\section{Visión sintética de una educación matemática holística y crítica}

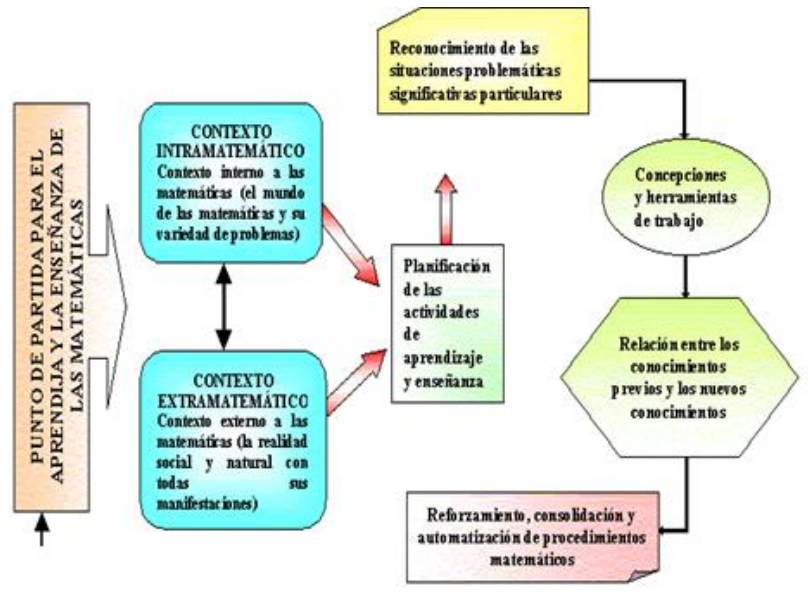

Figura 1 Estrategias para el aprendizaje y la enseñanza de la Matemática MORA, Castor David (2003) 
Según la figura presentada una posibilidad para iniciar el proceso de aprendizaje y enseñanza de la Matemática se trata del contexto interno a la Matemática, [2] el mundo de la Matemática, para muchos autores descontextualizado pero significativo.

La concepción sobre resolución de problemas internos a la Matemática juega un papel muy importante. Los estudiantes tanto en la escuela básica como en la educación secundaria y en la educación superior pueden disfrutar, entretenerse, interesarse y trabajar activamente alrededor de situaciones internas a la Matemática, siempre que ellas sean significativamente importantes e interesantes para los estudiantes.

\section{Verificación de la Hipótesis}

Para solucionar el problema descrito, y conforme la hipótesis planteada, se trabajó con las frecuencias observadas, con respecto a la aceptación del uso del Geo-Gebra como Herramienta Didáctica para mejorar el aprendizaje del tema de un sistema de inecuaciones de primer grado.

\section{Resultados.}

Pregunta No 1 ¿Mencione el rango de edad en que se encuentra?

Tabla 1 Edad de los docentes

\begin{tabular}{llc}
\hline $\begin{array}{l}\text { iMencione el rango de } \\
\text { edad en que se } \\
\text { encuentra? }\end{array}$ & f & \% \\
\hline 26 a 30 años & 0 & 0.00 \\
31 a 35 años & 2 & 33,33 \\
36 a 40 años & 0 & 0 \\
46 a 50 años & 2 & 33,33 \\
51 a 55 años & 2 & 33,33 \\
\hline
\end{tabular}

Gráfico 1 edad de los docentes

\section{Edad de los docentes}

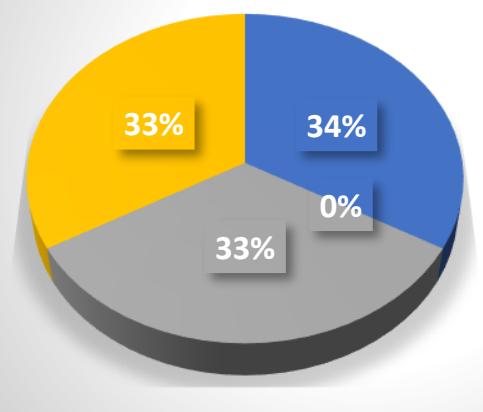

$$
\begin{aligned}
& -31 \text { a } 35 \text { años } \\
& -36 \text { a } 40 \text { años } \\
& 46 \text { a } 50 \text { años } \\
& 51 \text { a } 55 \text { años }
\end{aligned}
$$


Análisis e interpretación: El 33.33\% de los docentes comprendidos en la edad de entre los 31 y 35 años, un $33.33 \%$, 46 y 50 años y otro $33.33 \%$ entre 51 y 55 años. Se nota un grupo de docentes de edad con una gran experiencia, quienes en sus inicios como docentes no conocieron de las tecnologías como aplicaciones en sus actividades, por lo que su actitud ante los cambios será un muy significativa para la utilización de las TIC en su trabajo.

Pregunta No.2 ¿Cuántos años tiene como docente enseñando matemática?

Tabla 2 Años de docencia enseñando matemática

¿Cuántos años tiene en la docencia enseñando matemática?

f $\%$

\begin{tabular}{lcc}
\hline 1 a 5 años & 2 & 33,33 \\
6 a 10 años & 2 & 33,33 \\
11 a 15 años & 1 & 16,67 \\
16 a 20 años & 1 & 16,67 \\
21 a 30 años & 0 & 0 \\
\hline
\end{tabular}

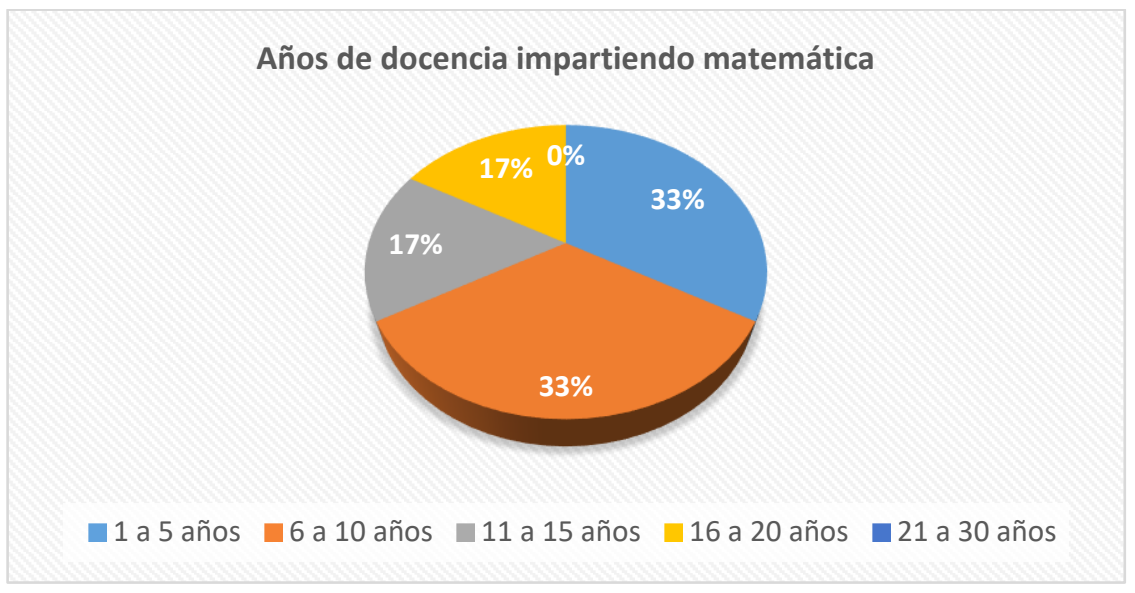

Gráfico 2 Tiempo de enseñanza

Pregunta No. 3 Seleccione los tipos de software que sabe usar

Tabla 3 Tipos de software utilizados por los docentes

\begin{tabular}{lcc}
\hline \multicolumn{1}{c}{ Seleccione los tipos de software que sabe usar } & F & \% \\
\hline Sistema operativo (Windows) & 6 & 100 \\
Procesador de texto (Word) & 6 & 100 \\
Hoja de cálculo (Excel) & 6 & 100 \\
Navegadores (Chrome, Firefox, internet Explorer) & 6 & 100 \\
Programa de presentaciones (PowerPoint) & 6 & 100 \\
Otro (especifique) & 1 & 16,67 \\
\hline
\end{tabular}


Tipos de software utlizados por los docentes

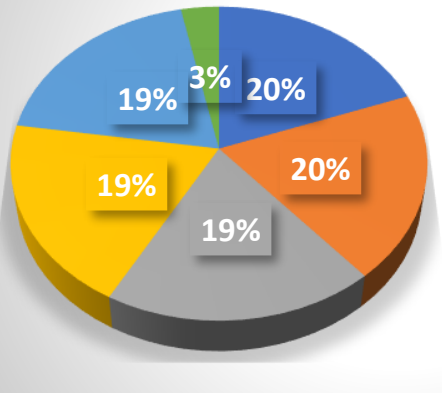

- Sistema operativo (Windows)

Procesador de texto (Word)

- Hoja de cálculo (Excel)

Gráfico 3 Tipos de software que utilizan los docentes

Análisis e interpretación: Del 100\% de docentes en los diferentes tipos de software básicos, el 16,67\% que equivale a 1 docente declara que utiliza una aplicación matemática.

Pregunta No. 4 ¿Cómo considera su destreza frente al computador como herramienta de trabajo?

Tabla 4 Destreza frente al computador

\begin{tabular}{lcc}
\hline $\begin{array}{l}\text { ¿Cómo considera su destreza frente al computador } \\
\text { como herramienta de trabajo? }\end{array}$ & f & \% \\
\hline Muy bueno & 1 & 16,67 \\
Bueno & 3 & 50 \\
Regular & 2 & 33,33 \\
Deficiente & 0 & 0 \\
\hline
\end{tabular}

Destreza frente al computador

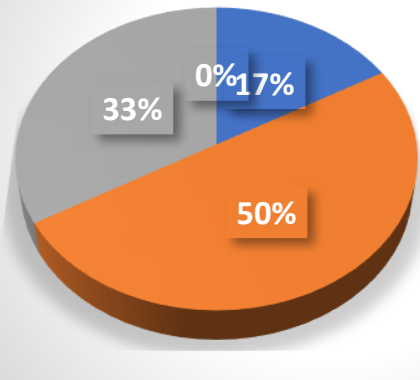

Muy bueno

Bueno

Regular

Deficiente

Gráfico 4 Destrezas frente al computador

Análisis e interpretación: El 50\% de los encuestados afirma que tiene una gran destreza frente al computador es bueno, un $17 \%$ califica su dominio como muy bueno. Afirmando que la destreza frente al computador es satisfactoria. 
Pregunta No.5 ¿Cuál es el nivel de motivación de sus estudiantes en el estudio de sistemas de Inecuaciones de primer grado?

Tabla 5 Nivel de motivación de los estudiantes en el estudio de sistemas de inecuaciones de primer grado

\begin{tabular}{lcc}
\hline $\begin{array}{l}\text { ¿Cuál es el nivel de motivación de sus estudiantes hacia } \\
\text { el estudio de sistemas de inecuaciones de primer grado? }\end{array}$ & f & $\%$ \\
\hline Muy alta & 0 & 0 \\
Alta & 1 & 16,67 \\
Media & 4 & 66,66 \\
Baja & 1 & 16,67 \\
\hline
\end{tabular}

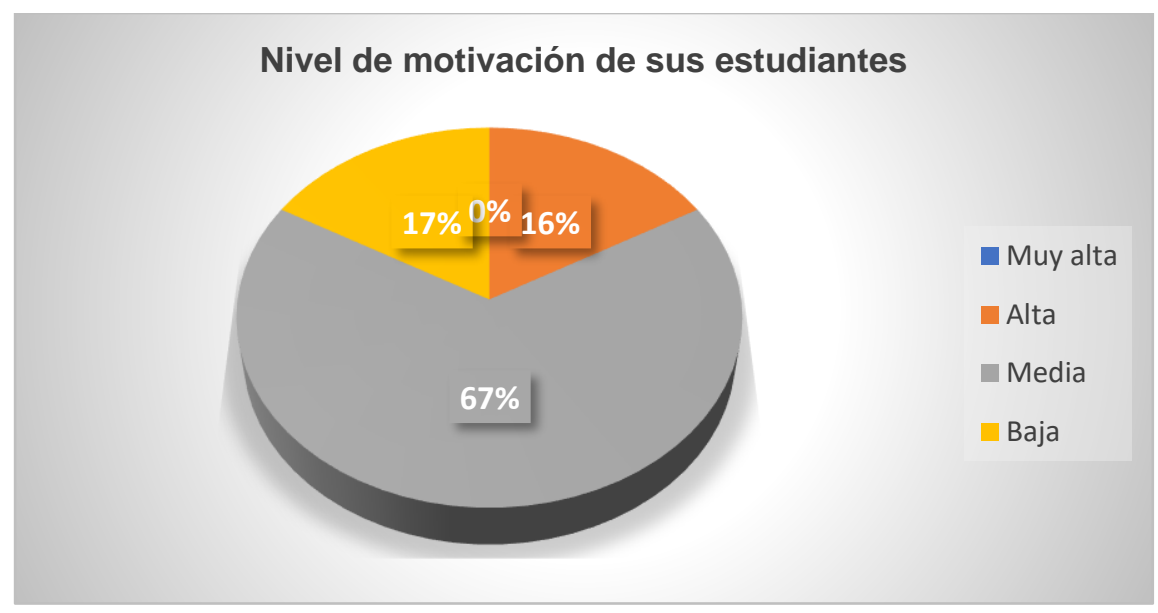

Gráfico 5 Nivel de motivación de los estudiantes en el estudio de sistemas de inecuaciones de primer grado

Análisis e interpretación: Un 67\% manifiesta que los estudiantes tienen un nivel de motivación medio hacia el estudio de Funciones de Variable Real, un 17\% afirma que es alta y el mismo porcentaje indica que es baja, lo cual da la idea que los estudiantes están dispuestos a estudiar el sistema de Inecuaciones de primer grado.

Pregunta No. 6 ¿Qué calificativo les otorga a los conocimientos previos que demuestran los estudiantes en matemáticas?

Tabla 6 Valoración de los conocimientos previos en matemáticas

\begin{tabular}{lcc}
\hline $\begin{array}{l}\text { ¿Qué valoración le otorga a los conocimientos previos } \\
\text { que demuestran los estudiantes en matemáticas? }\end{array}$ & f & $\%$ \\
\hline Muy Buenos & 0 & 0 \\
Buenos & 0 & 0 \\
Regulares & 4 & 66,67 \\
Deficientes & 2 & 33,33 \\
\hline
\end{tabular}




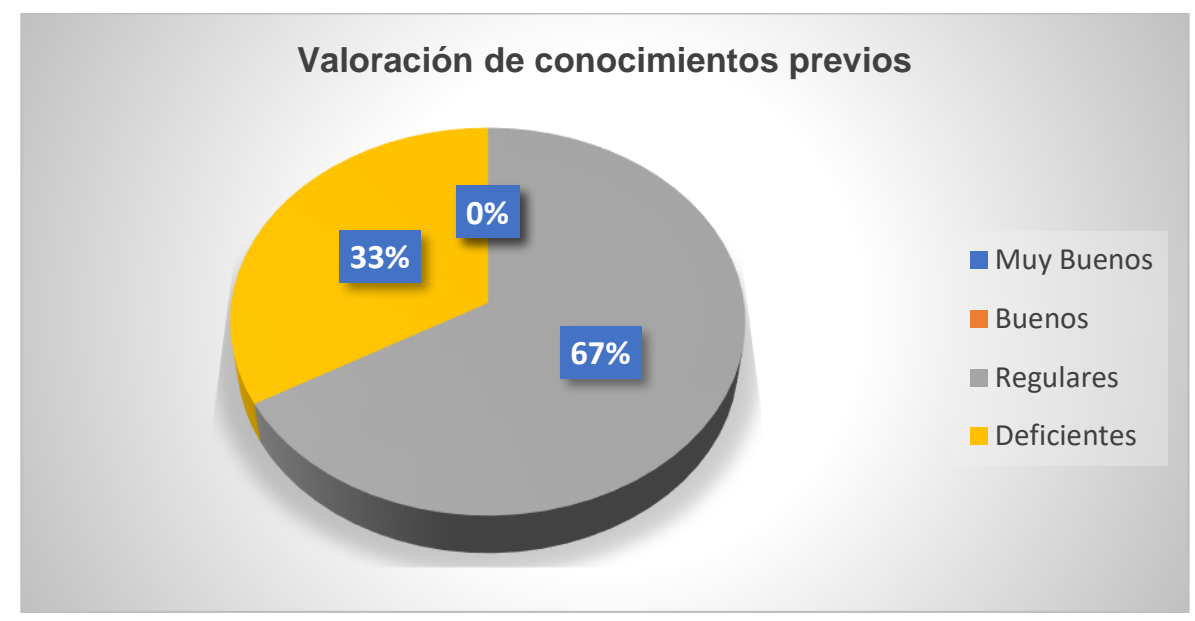

Gráfico 6: Valoración de los conocimientos previos en matemáticas

Análisis e interpretación: El $67 \%$ cree que los conocimientos previos son aceptables frente al $33 \%$ que dicen que tales conocimientos son deficientes. Donde se analiza que los conocimientos del estudiante visto desde el punto de vista del docente son bajos.

Se puede observar además que hay una deficiencia en toda el área de Matemática, en cuanto a los docentes.

Pregunta No. 7 ¿A qué causas le atribuye el bajo rendimiento en el tema de inecuaciones de primer grado?

Tabla 7 Causas del bajo rendimiento de los estudiantes en el estudio de sistemas de Inecuaciones

\begin{tabular}{lcc}
\hline $\begin{array}{c}\text { ¿Qué causas le atribuye el bajo rendimiento en el tema } \\
\text { de sistema de Inecuaciones? }\end{array}$ & f & \% \\
\hline Deficiencia de conocimientos previos & 5 & 83.33 \\
Estructura del material didáctico & 3 & 50.00 \\
Poco interés del estudiante & 2 & 33.33 \\
Poca participación del estudiante & 2 & 33.33 \\
Otro (especificar) & 1 & 16.67 \\
\hline
\end{tabular}




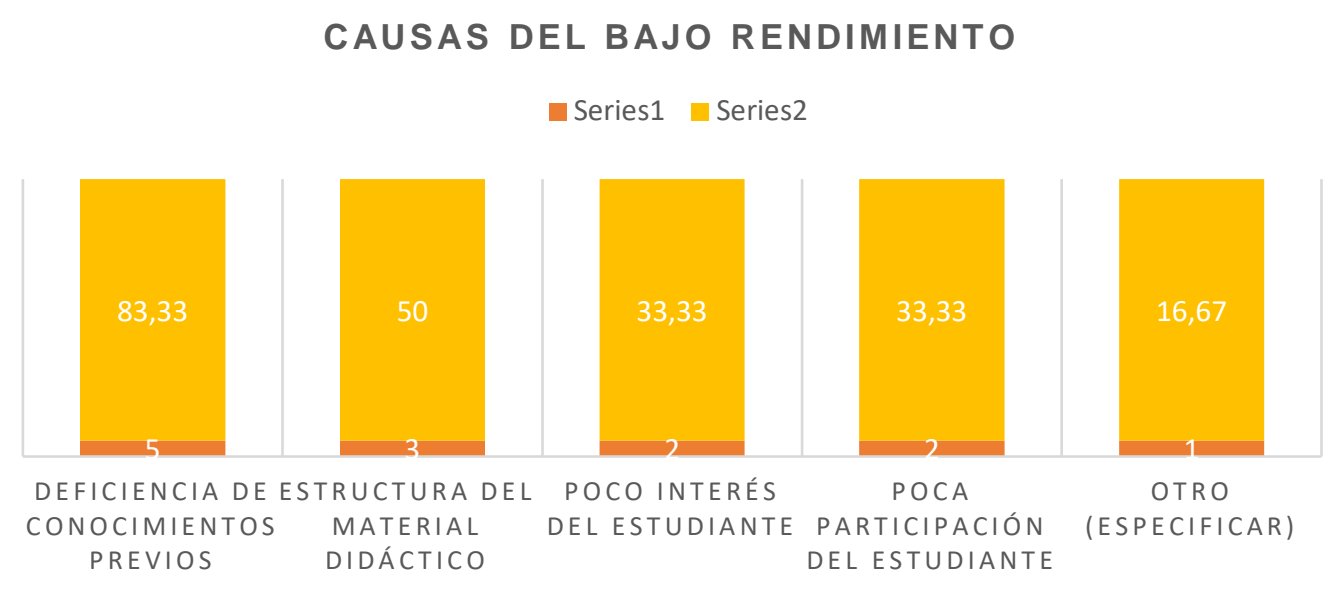

Gráfico 7 Causas del bajo rendimiento de los estudiantes en el estudio del sistema de Inecuaciones

Análisis e interpretación: El $83.33 \%$ piensa que el rendimiento es por deficiencia de conocimientos previos, el $50 \%$ piensa que se debe a la estructura tradicional, el $33.33 \%$ da a conocer que es por razón poco interés del estudiante, un docente especificó que es responsabilidad compartida.

Pregunta No.8 Usted como docente, ¿cómo considera el estudio y aplicación de los sistemas de Inecuaciones de primer grado?

Tabla 8: Consideración al estudio del sistema de inecuaciones de primer grado

\begin{tabular}{lcc}
\hline $\begin{array}{c}\text { ¿Cómo considera el estudio del sistema } \\
\text { de Inecuaciones de primer grado? }\end{array}$ & f & $\%$ \\
\hline Muy importante & 6 & 100 \\
Importante & 0 & 0 \\
Poco importante & 0 & 0 \\
Nada importante & 0 & 0 \\
\hline
\end{tabular}

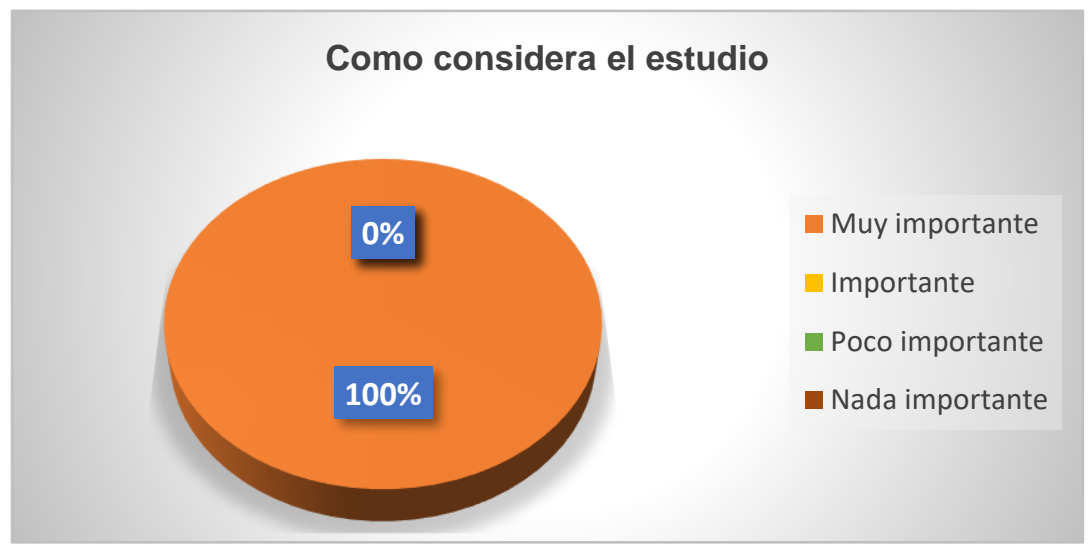

Gráfico 8 Consideración al estudio de Inecuaciones de primer grado 
Análisis e interpretación: El 100\% de los docentes encuestados manifiestan que estudiar el sistema de inecuaciones es muy importante.

Pregunta No. 09 ¿Qué tipo de recursos emplea para impartir el tema del sistema de inecuaciones de primer grado?

Tabla 9 Recursos utilizados para explicar el tema el sistema de inecuaciones

\begin{tabular}{lcc}
\hline $\begin{array}{l}\text { iQué tipo de recursos emplea para explicar el tema de } \\
\text { inecuaciones de primer grado? }\end{array}$ & F & $\%$ \\
\hline Pizarra & 6 & 100 \\
Computador con infocus & 2 & 33,33 \\
Otro & 0 & 0 \\
\hline
\end{tabular}

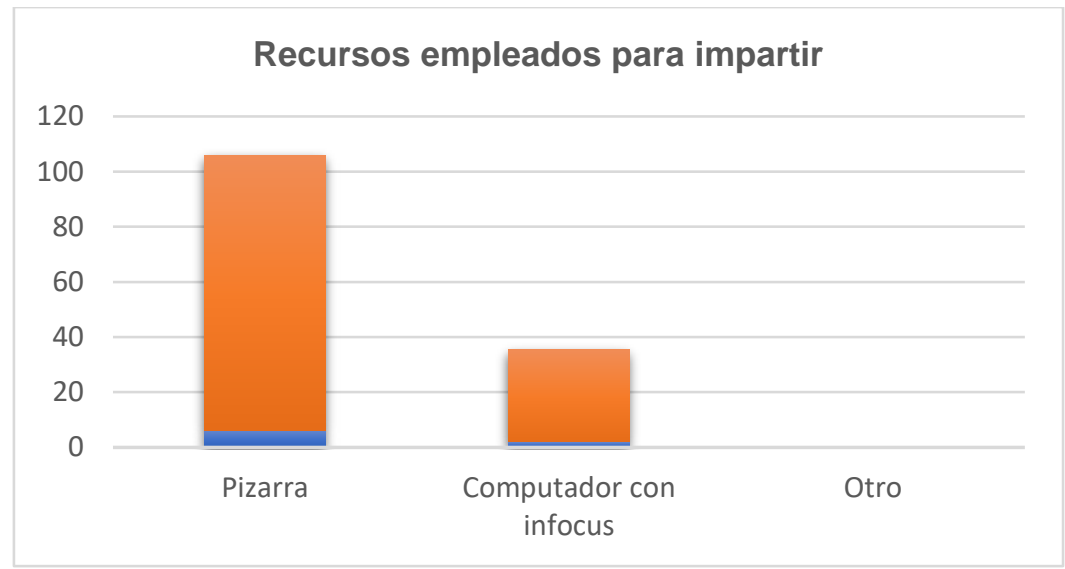

Gráfico 9 Recursos empleados para explicar el tema de inecuaciones

Análisis e interpretación: El 100\% de los docentes utilizan la pizarra, mientras que un $33.33 \%$ emplea el computador con infocus. De esta manera se ve que el docente está utilizando principalmente para la enseñanza de las matemáticas la pizarra dejando a segundo plano las herramientas tecnológicas.

Pregunta No. 10 ¿Qué estrategias recomienda implementar para la unidad de sistemas de inecuaciones de primer grado?

Tabla 10 Estrategias recomendadas para la unidad de sistemas de inecuaciones de primer grado

\begin{tabular}{lcc}
\hline $\begin{array}{l}\text { ¿Qué estrategias recomienda implementar en la } \\
\text { unidad de sistema de inecuaciones de primer grado? }\end{array}$ & f & $\%$ \\
\hline Utilizar Objetos de aprendizaje & 5 & 83.33 \\
Propiciar clases más participativas & 4 & 66.67 \\
Realizar talleres en grupo & 2 & 33.33 \\
Otro & 0 & 0 \\
\hline
\end{tabular}




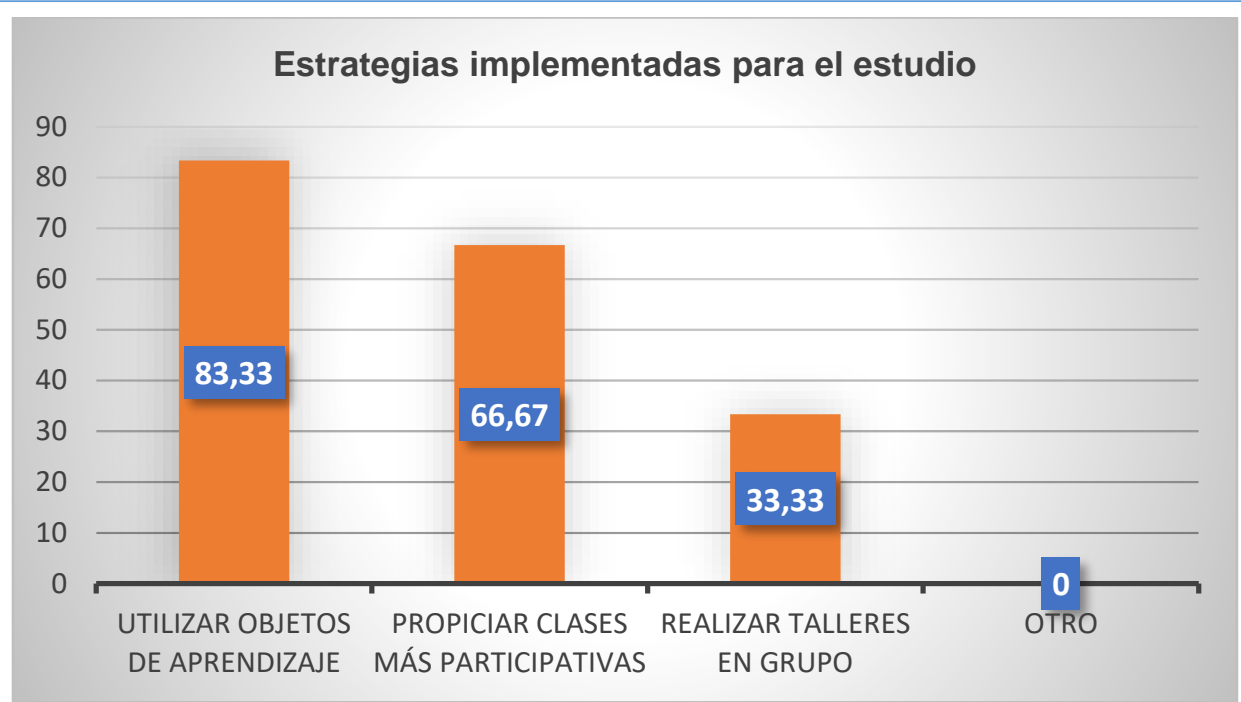

Gráfico 10 Estrategias recomendadas para que el tema de inecuaciones de primer grado

Análisis e interpretación: El 83.33\% recomiendan utilizar objetos de aprendizaje, un $66.67 \%$ recomiendan propiciar clases más participativas, y un $33.33 \%$ realizar talleres en grupo. Notoriamente existe la tendencia a utilizar recursos audiovisuales interactivos además con clases participativas.

Pregunta No. 11 ¿Piensa usted que en la actualidad, docentes y estudiantes deben emplear las tecnologías de información y comunicación (TIC)?

\section{Tabla 11 Empleo de los docentes y estudiantes de las TIC}

¿Piensa usted que en la actualidad, docentes y estudiantes deben emplear las tecnologías de información y comunicación (TIC)?

\begin{tabular}{lcc}
\hline $\mathrm{Si}$ & 6 & 100 \\
$\mathrm{No}$ & 0 \\
\hline
\end{tabular}

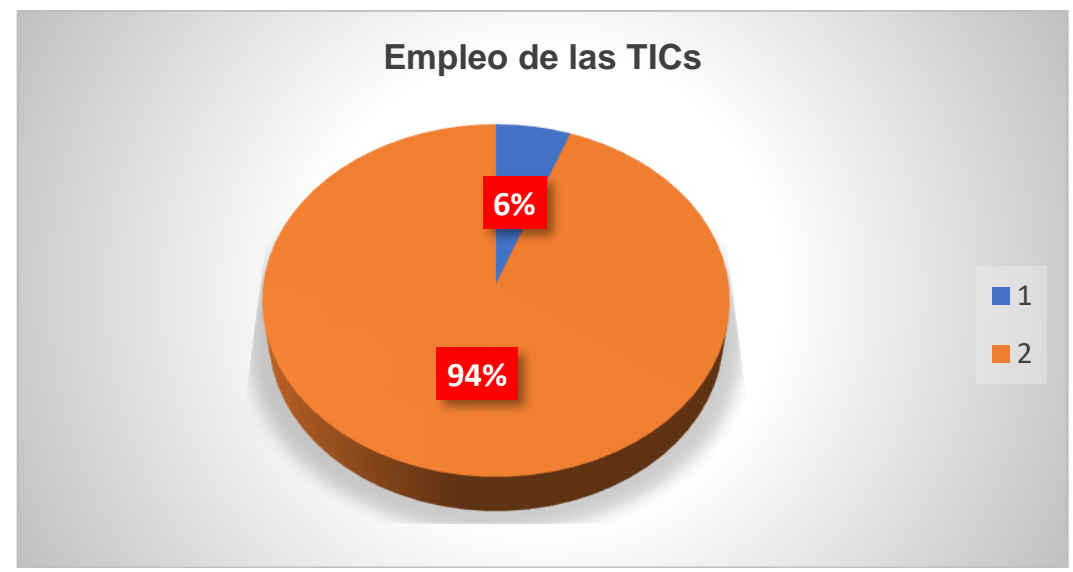

Gráfico 11 Preparación de los docentes y estudiantes con las TIC 
Análisis e interpretación: El 100\% de los encuestados afirman que tanto los docentes como los estudiantes deben utilizar las TIC. Evidentemente, no se puede ser neófito de la realidad actual, no solo los docentes y estudiantes, sino que la sociedad en general necesita de las TIC para formar ideas y criterios propios sobre cualquier tema.

Pregunta No. 12 ¿Estaría de acuerdo en disponer de un recurso didáctico que le permita motivar a los estudiantes en el estudio de las matemáticas?

Tabla 12 Acuerdo para disponer un recurso didáctico

\begin{tabular}{lcc}
$\begin{array}{l}\text { ¿Estaría de acuerdo en disponer de un recurso didáctico } \\
\text { que le permita motivar a los estudiantes en el estudio de } \\
\text { las matemáticas? }\end{array}$ & f \\
\hline $\mathrm{Si}$ & 6 & 100 \\
$\mathrm{No}$ & 0 & 0 \\
\hline
\end{tabular}

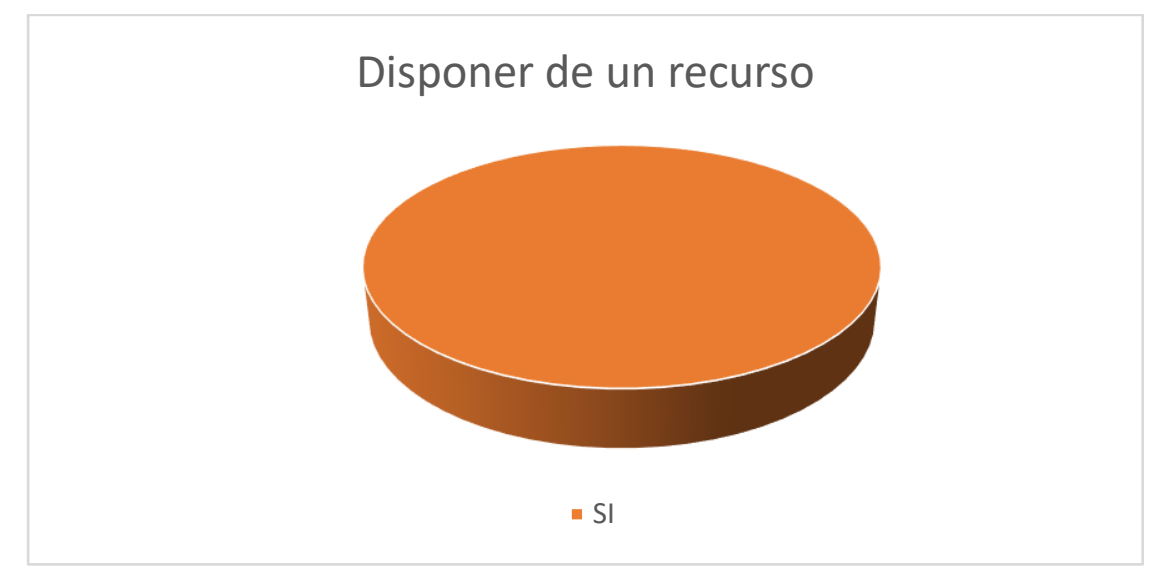

Gráfico 12: Agrado de disponer un recurso didáctico

Análisis e interpretación: Al 100\% de los docentes encuestados de acuerdo utilizar un recurso didáctico para impartir sus clases de matemáticas. Los docentes por unanimidad coinciden con la idea de disponer un recurso tecnológico para facilitar y motivar las clases de matemáticas.

Pregunta No. 13 ¿Promovería la utilización de un Software Educativo en la Carrera?

Tabla 13 Promover la utilización de un software educativo

\begin{tabular}{lcc}
\hline ¿Promovería la utilización de un & f & $\%$ \\
Software Educativo en la Carrera? & & \\
$\mathrm{Si}$ & 6 & 100 \\
$\mathrm{No}$ & 0 & 0 \\
\hline
\end{tabular}




\section{Utilización de un software educativo}

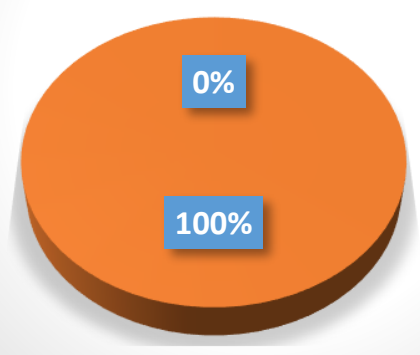

Gráfico 13 Participación a experimentar un software educativo

Análisis e interpretación: El 100\% de los encuestados Promovería la utilización de un Software Educativo en la Carrera. Donde se concluye que los docentes están dispuestos aplicar software educativo en la enseñanza de las matemáticas.

Pregunta No. 14 ¿Agregaría alguna información o inquietud relevante que no se haya preguntado en este cuestionario?

Tabla 14 Información o inquietud adicional de los docentes

\section{¿Desearía agregar alguna información o inquietud relevante que no se haya preguntado en este cuestionario?}

Se debe tomar muy en cuenta el número de estudiantes por aulas, no

1 deben exceder de 30 estudiantes por paralelo y de esta manera se aportaría en gran medida la enseñanza en las aulas de clases.

¿Cómo se resolvería el problema de falta de infraestructura adecuada

2 y la implementación de equipos de cómputo? Por lo que algunos estudiantes no disponen con un computador portátil.

Análisis e interpretación: Dos encuestados muestran, por un lado, la inquietud que solo debe de haber como máximo 30 estudiantes por paralelo en los niveles básicos, y el otro la preocupación de la infraestructura y la implementación de equipos.

\section{ANÁLISIS CUANTITATIVO DEL GRUPO DE EXPERIMENTACIÓN}


Cálculos estadísticos

Tabla 15 Cuadro resumen de calificaciones obtenidas

\begin{tabular}{|c|c|c|c|c|}
\hline \multirow[b]{2}{*}{$\begin{array}{c}\text { ESCALAS DE } \\
\text { CALIFICACIÓN } \\
\end{array}$} & \multicolumn{2}{|c|}{ CON EL GEO-GEBRA } & \multicolumn{2}{|c|}{ SIN EL GEO-GEBRA } \\
\hline & $\begin{array}{c}\mathbf{N}^{\circ} \\
\text { ESTUDIANTES }\end{array}$ & $\%$ & $\begin{array}{c}\mathbf{N}^{\circ} \\
\text { ESTUDIANTES }\end{array}$ & $\%$ \\
\hline $\begin{array}{l}\text { Aprueban la asignatura (25 a } \\
\text { 28) }\end{array}$ & 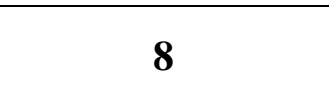 & 27 & 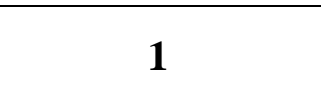 & 3 \\
\hline Quedan suspensos (16-24) & 20 & 67 & 10 & 33 \\
\hline $\begin{array}{l}\text { Reprueban la asignatura (7- } \\
\text { 14) }\end{array}$ & 2 & 7 & 19 & 63 \\
\hline $\begin{array}{l}\text { Retiraron matricula de la } \\
\text { signatura }\end{array}$ & $\mathbf{0}$ & $\mathbf{0}$ & $\mathbf{0}$ & $\mathbf{0}$ \\
\hline TOTAL & 30 & 100 & 30 & 100 \\
\hline
\end{tabular}

Luego del resultado obtenido del análisis de las encuestas aplicadas a los estudiantes de los décimos años de educación general básica se obtiene:

$$
\mathrm{X}^{2}=7,81 \quad \mathrm{X}_{\mathrm{c}}{ }_{\mathrm{c}}=22,54
$$

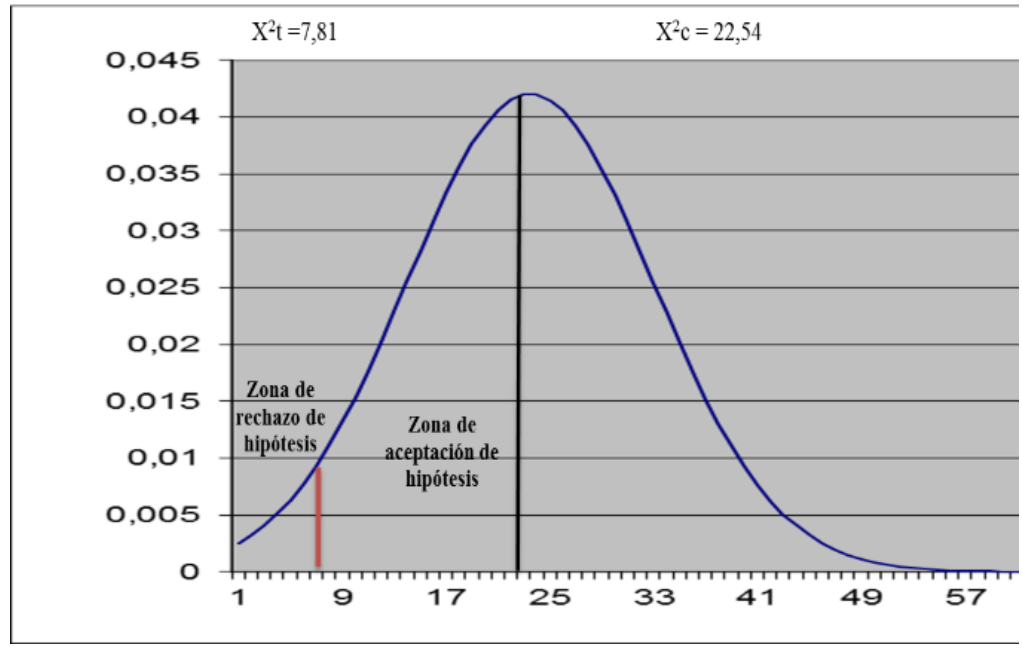

Comprobación de la hipótesis

Fuente: Distribución del Chi-cuadrado.

Dado que el valor del chi cuadrado calculado $(22,54)$ es mayor al chi cuadrado tabulado $(7,81)$ el resultado es altamente significativo, es decir que el rendimiento académico de los estudiantes que usaron Geo-Gebra como Herramienta de apoyo didáctico en la enseñanza de tema de inecuaciones de primer grado, supera al rendimiento de los estudiantes que no lo usaron.

\section{Conclusiones.}

Al realizar esta investigación logró fortalecer el uso de las tecnologías de información y comunicación, en la educación y los beneficios en la enseñanza como en el aprendizaje de la 
matemática, así como las condiciones actuales en la que se encuentran tanto alumnos como docentes en relación con el uso de las TIC en la carrera.

Es preciso mencionar |que las conclusiones que se enuncian son válidas para este estudio en particular.

Así podemos concluir que:

- Se comprobó que los docentes de la carrera no utilizan las TIC en el desarrollo de sus clases en la materia de Matemática

- Dado que el valor del chi cuadrado calculado $(22,54)$ es mayor al chi cuadrado tabulado $(7,81)$ el resultado es altamente significativo, es decir que el rendimiento académico de los estudiantes que usaron GEO-GEBRA en la enseñanza de los temas de sistemas de inecuaciones de primer grado, supera al rendimiento de los estudiantes que no lo usaron, es decir: la aplicación GEO-GEBRA de Matemática incide significativamente en el desempeño académico de los estudiantes; lo que permitiría suponer que ésta hipótesis es aplicable y general a grupos semejantes.

- Realizar capacitaciones y talleres del manejo y uso de las TIC por parte de los docentes, así como del manejo del software libre Geo-Gebra.

- Emplear la misma metodología didáctica con un número mayor de computadores para determinar si la tendencia de crecimiento de la función entre variables crece por lo tanto compartir y socializar este trabajo con las instituciones semejantes y cercanas a la institución investigada, para que se pueda dar continuidad a la utilización GeoGebra en Matemática, y de esta manera lograr incidir positivamente en el rendimiento académico de los estudiantes de esas instituciones educativas.

\section{Referencias bibliográficas.}

[1] G. A. Pedro, «http://dspace.espoch.edu.ec/handle/123456789/6827,» 1107 2017. [En línea]. Available: http://dspace.espoch.edu.ec/handle/123456789/6827. [Último acceso: 25 02 2018].

[2] F. J. Córdoba Gómez, «LAS TIC EN EL APRENDIZAJE DE LAS MATEMÁTICAS: ¿QUÉ CREEN LOS ESTUDIANTES?,» Congreso Iberoamericano de Ciencia, Tecnología, Innovación y Educación, no ISBN: 978-84-7666-210-6 - Artículo 1571, p. $9,2014$.

[3] F. d. 1. C. Salaiza Lizárraga, «Diferencia en el uso de las tecnologías de información y comunicación entre docentes y alumnos de nivel superior ¿Una brecha digital?,» Revista de Investigación Educativa de la Escuela de Graduados en, $n^{\circ}$ 7, p. 17, 4.

[4] S. D. P. A. ZAPATA, «ELABORACIÓN Y APLICACIÓN DEL USO DE UNA GUÍA DE MODELO VIRTUAL Y SU INCIDENCIA EN EL PROCESO DE APRENDIZAJE DE CINEMÁTICA DE LOS ESTUDIANTES DEL PRIMERO DE BACHILLERATO ESPECIALIDAD ELECTROMECÁNICA AUTOMOTRIZ PARALELO “B” DEL INSTITUTO TECNOLÓGIC,» RIOBAMBA, 2015.

[5] Hernández Requena, Stefany ; «El modelo constructivista con las nuevas tecnologías: aplicado en el proceso de aprendizaje,» https://educrea.cl/el-modeloconstructivista-con-las-nuevas-tecnologias-aplicado-en-el-proceso-de-aprendizaje/. 
[7] R. Stallman, «https://www.gnu.org/education/education.es.html,» 1811 2016/11/18. [En línea]. Available: https://www.gnu.org/education/education.es.html. [Último acceso: 05 05 2018].

[8] M. P. P. Espinosa, «Análisis comparativo de la universidades españolas,» PLATAFORMAS DE CAMPUS, p. 228, 2009.

[9] «http://luzmarinadelacruzmartinez.blogspot.com/,» [En línea]. Available: http://luzmarinadelacruzmartinez.blogspot.com/. [Último acceso: 0505 2018].

[10] M. B. A. B. -. G. B. Z., «Los usos de Internet comunicación y socieda,» Quito, Rispergraf, 2006.

[11] G. K. Juan Raul, «Nuevas tecnologías de la Educación y software libre,» La revista, $\mathrm{n}^{\circ} 8$, p. 35, 2006.

[12] MINEDUC, «Www.educación.gob.ec,» 2010. [En línea]. Available: http://www.educar.ec/noticias/7moanio.pdf. 


\section{Para citar el artículo indexado.}

Martínez Nogales, J., Cachuput Gusñay, J., Chamarro Sevilla, H., \& López Ortega, J. (2019). Geogebra como herramienta didáctica en el proceso de enseñanza-aprendizaje de la matemática, y su incidencia en el rendimiento académico en los estudiantes de la carrera de ingeniería agronómica. Explorador Digital, 3(3.1), 204-223. https://doi.org/10.33262/exploradordigital.v3i3.1.881

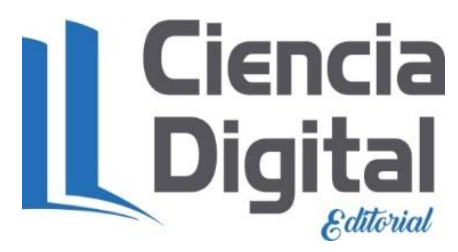

El artículo que se publica es de exclusiva responsabilidad de los autores y no necesariamente reflejan el pensamiento de la Revista Explorador Digital.

El articulo queda en propiedad de la revista y, por tanto, su publicación parcial y/o total en otro medio tiene que ser autorizado por el director o editor de la Revista Explorador

Digital.
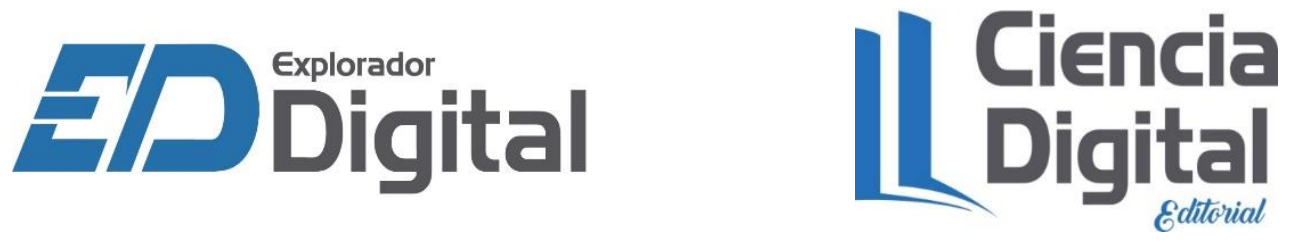